\title{
The likely success of functional analysis tied to the DSM
}

\author{
Richard T. Bissett, Steven C. Hayes* \\ Department of Psychology/296, University of Nevada, Reno, NV 89557, U.S.A.
}

\begin{abstract}
Nelson-Gray and Farmer argue that behavioral assessment and functional analysis may be beneficially applied to personality disorders (PDs). While this is a reasonable response to the largely nonbehaviorally derived Diagnostic and Statistical Manual (DSM), it is not yet clear that grafting such theoretically incongruent elements will be viable. In essence, they argue that a syndromal classification system could serve a nomothetic role of guiding a functional, idiographic analysis. This is possible, but it seems unlikely that this process would remain in equilibrium, with no interactive effect of the functional analysis on the syndromes themselves. Yet the DSM system has shown itself to be surprisingly closed to a more functional approach, so the relationship between the DSM and functional analysis is not open in both directions. What is needed is a nomothetic level of analysis that is also functionally derived. The primary benefit of functional over syndromal categories is one of treatment utility, a concept that is itself surprisingly absent from the authors' otherwise comprehensive discussion of behavioral assessment. (C) 1999 Elsevier Science Ltd. All rights reserved.
\end{abstract}

Keywords: Behavioral assessment; Treatment utility; Functional analysis

\section{The likely success of functional analysis tied to the DSM}

Nelson-Gray and Farmer argue that there is a synergistic benefit in augmenting the DSM syndromal classification of PDs with behavioral, functional assessment, and argue that a nomothetic categorization system is valuable in providing a place to begin a functional analysis. In effect, the authors describe how many behavioral clinicians currently cope with a syndromal classification paradigm that is often incongruent with behavioral theory. While we agree that the DSM can and often does serve this initial role, we are not sure that this is the best place to start, nor that the relationship is ultimately sustainable and mutual.

\footnotetext{
* Corresponding author.
} 
Some nomothetic conceptual overlay is necessary as an initial guide to the more in-depth process of individual functional analysis because it defines the domain of interest (Hayes \& Follette, 1992). While it is initially reasonable to treat a syndromal classification system merely as a set of co-varying behaviors subject to idiographic analysis (e.g. Nelson \& Barlow, 1981), the concept of "syndrome" within the DSM is more theoretical, coherent, and thus resistant to change than a mere collection of behaviors. DSM syndromes are essentially prototypes (Hayes \& Follette, 1992) — "a slowly evolving accretion of clinical experience..., fostered and formalized periodically by the systematizing efforts of respected clinician-scholars" (Millon, 1991). This prototypical nature of the DSM is evidenced by the extreme case of individuals receiving the same diagnosis, but not sharing a single diagnostic characteristic (Frances, Pincus, Widiger, Davis \& First, 1990), and by an internal consistency of symptoms within PDs of only 0.10 to 0.29 (Morey, 1988).

In addition, DSM syndromes are deliberately and decidedly topographical. In the area of behavioral health, several distinct functional processes may explain a particular topography, and distinct topographies may result from the same underlying process. For example, overdrinking can have multiple functions, such as social compliance and avoiding painful emotions. Similarly, the same function-such as avoiding painful emotions-can control multiple behaviors, such as overdrinking, overworking, bingeing, sexual promiscuity, and so on. Nelson-Gray and Farmer's idea requires, however, that topography feed the discovery of functional processes. There seems to be little evidence that a nosology emphasizing form is helpful when the goal is to explain function. Consider, for example, the issue of treatment utility.

\subsection{The treatment utility of the DSM nosology}

A major weakness of the DSM is the very limited ability to use syndromes to determine etiology, choice of treatment, and treatment response. Empirical evidence on this point is more lacking than actively disconfirming (Kratochwill \& Plunge, 1992; Kratochwill \& McGivern, 1996) but there are many reasons to believe that there is a problem. Syndromal assessment is only weakly linked to differential treatment, for example (Callahan, Panichelli-Mindel \& Kendall, 1996; Gresham \& Gansle, 1992; Hayes, Nelson \& Jarrett, 1987; Korchin \& Schuldberg, 1981; McReynolds, 1985). Logically, no diagnostic system can make much of a difference at the level of treatment outcome until it produces reliably differential treatment linked to the diagnostic categories. The poor correlation between syndromes and treatment is demonstrated by the application of essentially the same treatment technologies across a broad range of syndromal disorders, such as the application of cognitive therapy to mood (Beck, Rush, Shaw \& Emery, 1979), anxiety (Michelson \& Ascher, 1987), and personality (Beck \& Freeman, 1990) disorders, with only minimal change.

If the DSM had treatment utility it would suggest that there is a functional process engaged by these topographical distinctions that remained to be discovered. Without this evidence, however, there is no logical reason to believe that a functional analysis built on the DSM will necessarily identify important functional processes. To take an example, suppose the DSM nosology was built upon tone or loudness of voice and the physical posture of clients. These features, even if they could be reliably identified and clustered, would probably never yield 
either treatment utility or important functional analyses. Even if they did, however, an additional problem would remain: would the topographical classification system be able to change as a result?

\subsection{Can functional analysis change syndromal classification?}

Even if functional analyses can be built on a DSM foundation, there is no indication that a long-term and mutually beneficial relationship would be produced. Nelson-Gray and Farmer see the problems with the DSM system, but they give too little emphasis to the problems of grafting a functional analysis onto a syndromal classification system. For example, the authors justifiably worry about apparent contradictions between concepts central to behavioral assessment and personality disorder-e.g. the state/trait distinction-but are unconcerned about the contradiction of melding a system emphasizing topographical structure with an analytic process emphasizing functions of behavior. The article "seeks to describe how concepts within a behavioral model can provide a useful framework for the assessment of PDs and PD features" (p. 3). Yet providing such a framework is just what a behavioral model is prevented from doing due to the entrenched presence of a largely non-behavioral framework - the DSM nosology itself.

An unfettered functional analysis would be free to re-categorize the original classifications along functional lines. In fact, this would be the only possible outcome if functional analysis were nomothetically successful. A large set of functional analyses may reveal common functional processes. This could lead to a nomothetic level of analysis that is also functionally derived - a classification system based on functional categories. But the entire rationale behind the DSM (its supposedly atheoretical and syndromal approach) is biased against incorporating such insights and permitting the reorganization of entities into functional categories based on behavioral principles or, indeed, theoretical principles of any kind.

Attaching a functional analysis to non-functionally conceived syndromes, while offering an additional analytic perspective, could legitimize non-functional syndromes with no realistic hope of modifying them based on knowledge of functional processes. Nelson-Gray and Farmer apparently do not see the one-way nature of the relationship they envision. If the introduction of a functional process in the assessment process cannot be allowed to disrupt any pre-existing syndromal classes and reform them along functional dimensions, then the long-term impact of functional analysis is arbitrarily limited.

\subsection{Functional analysis is not now prepared for a nomothetic role}

Classic functional analysis could yet be developed as a nomothetic method of diagnosis and classification (Hayes \& Follette, 1992). If this occurred, functional analysis would stand alone, an alternative to the DSM system, and have the benefit of being consistent with behavioral theory. Unfortunately, functional analysis, as presently conceived, is clearly not up to this task, primarily because it is neither specific nor replicable (Hayes \& Follette, 1992). Functional analysis is almost a generic term - there are many variants of this general process, and it is not clear which produces the best outcome. Poor specification and replication have meant that it has been a challenge to research classical functional analysis, as a process, in order to 
determine, for example, treatment utility (a few studies have attempted this challenge, e.g. Haynes \& O’Brien, 1990; McKnight, Nelson, Hayes \& Jarrett, 1984).

Addressing these concerns for specification and replication might well mean the development of an expert system or a logical algorithm approach to the method of functional analysis (Hayes \& Follette, 1992). These options would allow for a systematization of the analytical process. Once this goal was accomplished, the focus would turn to the development of functional diagnostic categories, which would naturally emerge from the repetition of individual functional analyses, all conducted in accordance with a standard analytic process. Examples of potential categories include disruptive behavior, such as inappropriate requests for attention or assistance (Carr \& Durand, 1985); self-injurious behavior, such as "attentiongetting, escape-maintained, tangibly-maintained, and sensory-maintained behaviors" (Durand \& Crimmins, 1988; p. 116); emotional avoidance (Hayes, Wilson, Gifford, Follette \& Strosahl, 1996); and disordered rule-following (Hayes, 1989).

\subsection{The utility of the Nelson-Gray and Farmer approach}

Nelson-Gray and Farmer review specific behavioral assessment methods and how these may be linked to specific interventions, but the authors do not provide evidence of the treatment utility of this very linkage. Instead the concept of utility that is used seems limited to political domains. The authors take the position that the DSM PD categories "have utility in the absence of overwhelming data to the contrary" (p. 5). The DSM undoubtedly provides a common nomenclature and it has been widely endorsed by the legal community and the health insurance industry (Follette, Houts \& Hayes, 1992), but the ultimate purpose of assessment is to inform distinctive treatment choices. We fear that the approach proposed is too vague to contribute to that outcome. For example, while a full assessment may include such items as "genetic predispositions, physiological correlates of the disorder, temperament, and appearance" (p. 11), it is not clear how this broad range of information can be utilized by the assessor.

In addition, the more specific positive outcomes described by the authors would occur without the formulation they suggest. For example, Nelson-Gray and Farmer argue that a delineation of prototypical emotional experiences characteristic of the PDs may prove valuable in developing treatment approaches (p. 23). If emotional factors are important, however, decent functional analyses would also determine this, and the guidance from the DSM is far too vague to be of obvious treatment utility.

\section{Summary}

We agree with Nelson-Gray and Farmer that the general domain of phenomena delineated by the concept "personality disorder" requires analysis and that a more functional approach can make a contribution to this endeavour. Our concern is that too much guidance by the DSM may only slow the contribution that might be made. Whether that is true is an empirical matter, but a better solution to us seems to be to hold the DSM very lightly and to work a classification system based on function by identifying functional diagnostic dimensions of 
known treatment utility (Hayes, Wilson, Gifford, Follette \& Strosahl, 1996). In this alternative, function would be the focus from beginning to end and we would not wait indefinitely for a demonstration of the treatment impact of the approach, as has occurred in the DSM system.

\section{References}

Beck, A. T., \& Freeman, A. (1990). Cognitive therapy of personality disorders. New York: Guilford Press.

Beck, A. T., Rush, A. J., Shaw, B. T., \& Emery, G. (1979). Cognitive therapy of depression. New York: Guilford Press.

Callahan, S. A., Panichelli-Mindel, S. M., \& Kendall, P. C. (1996). DSM-IV and internalizing disorders: Modifications, limitations, and utility. School Psychology Review, 25, 297-307.

Carr, E. G., \& Durand, V. M. (1985). Reducing problem behaviors through functional communication training. Journal of Applied Behavior Analysis, 18, 111-126.

Durand, V. M., \& Crimmins, D. B. (1988). Identifying the variables maintaining self-injurious behavior. Journal of Autism and Developmental Disorders, 18, 99-117.

Follette, W. C., Houts, A. C., \& Hayes, S. C. (1992). Behavior therapy and the new medical model. Behavioral Assessment, 14, 323343.

Frances, A., Pincus, H. A., Widiger, T. A., Davis, W. W., \& First, M. B. (1990). DSM-IV: Work in progress. American Journal of Psychiatry, 147, 1439-1448.

Gresham, F. M., \& Gansle, K. A. (1992). Misguided assumptions of DSM-III-R: Implications for school psychological practice. School Psychology Quarterly, 7, 79-95.

Hayes, S. C. (1989). Rule-governed behavior: Cognition, contingencies and instructional control. New York: Plenum.

Hayes, S. C., \& Follette, W. C. (1992). Can functional analysis provide a substitute for syndromal classification? Behavioral Assessment, 14, 345-365.

Hayes, S. C., Nelson, R. O., \& Jarrett, R. (1987). Treatment utility of assessment: A functional approach to evaluating the quality of assessment. American Psychologist, 42, 963-974.

Hayes, S. C., Wilson, K., Gifford, E. V., Follette, V. M., \& Strosahl, K. (1996). Experiential avoidance and behavioral disorders: A functional dimensional approach to diagnosis and treatment. Journal of Consulting and Clinical Psychology, 64, 1152-1168.

Hayes, S. N., \& O'Brien, W. H. (1990). Functional analysis in behavior therapy. Clinical Psychology Review, 10, $649-668$.

Korchin, S. J., \& Schuldberg, D. (1981). The future of clinical assessment. American Psychologist, 36, 1147-1158.

Kratochwill, T. R., \& McGivern, J. E. (1996). Clinical diagnosis, behavioral assessment, and functional analysis: Examining the connection between assessment and intervention. School Psychology Review, 25, 342-355.

Kratochwill, T. R., \& Plunge, M. (1992). DSM-III-R, treatment validity, and functional analysis: Further considerations for school psychologists. School Psychology Quarterly, 7, 227-232.

McKnight, D. L., Nelson, R. O., Hayes, S. C., \& Jarrett, R. B. (1984). Importance of treating individually-assessed response classes in the amelioration of depression. Behavior Therapy, 15, 315-335.

McReynolds, P. (1985). Psychological assessment and clinical practice: Problems and prospects. In J. N. Butcher, \& C. D. Spielberger (Eds.), Advances in personality assessment (4, pp. 1-30). Hillsdale, NJ: Erlbaum.

Michelson, L., \& Ascher, L. M. (1987). Anxiety and stress disorders: Cognitive-behavioral assessment and treatment. New York: Guilford Press.

Millon, T. (1991). Classification in psychopathology: Rationale, alternative, and standards. Journal of Abnormal Psychology, 100, 245261.

Morey, L. C. (1988). Personality disorders in DSM-III and DSM-III-R: Convergence, coverage, and internal consistency. American Journal of Psychiatry, 145, 573-577.

Nelson, R. O., \& Barlow, D. H. (1981). An overview of behavioral assessment with adult clients: Basic strategies and initial procedures. In D. H. Barlow (Ed.), Behavioral assessment with adults, (pp. 13-43). New York: Guilford. 